\title{
Impact of COVID-19 on Allergy Residency Training in Spain
}

Zambrano Ibarra $\mathrm{G}^{1}$, Posadas Miranda $\mathrm{T}^{2}$, Meijide Calderón A $^{3}$, Rial $\mathrm{MJ}^{4}$, and, GarcíaGutierrez I ${ }^{5}$ on behalf of the Commission of Young Allergists and MIR (CAJMIR) of Spanish Society of Allergology and Immunology (SEAIC)

${ }^{1}$ Allergy Service, Hospital General Universitario Gregorio Marañón, Madrid, Spain ${ }^{2}$ Allergy Service, Regional University Hospital, Málaga, Spain

${ }^{3}$ Allergy Service, Complexo Hospitalario Universitario de Vigo, Pontevedra, Spain ${ }^{4}$ Allergy Service, Complexo Hospitalario Universitario A Coruña, A Coruña, Spain

${ }^{5}$ Allergy Service, Hospital Universitario Marqués de Valdecilla, Santander, Spain

\section{Corresponding author:}

Gabriela Zambrano Ibarra

Allergy Service, General University Hospital Gregorio Marañón, Madrid, Spain 46 Dr Esquerdo Street. 28007 Madrid, Spain

E-mail: gaby_gazi@hotmail.com

This article has been accepted for publication and undergone full peer review but has not been through the copyediting, typesetting, pagination and proofreading process, which may lead to differences between this version and the Version of Record. Please cite this article as doi: 10.18176/jiaci.0790 
Key words: Allergy. Allergology. Residents. COVID-19. SEAIC

Palabras clave: Alergia. Alergología. Residentes. COVID-19. SEAIC

The COVID-19 pandemic has led to drastic changes in the Healthcare system.

The successive waves of the SARS-CoV-2 pandemic caused important healthcare modifications and contingency situations. The first wave of the pandemic caused the collapse of the Healthcare system, and a state of alarm was declared in March 2020 (RD 463/2020 and Order SND/232/2020) [1,2]. Subsequently, due to the care needs generated, the resident rotations were suspended in order to transfer them to the COVID-19 units (Order SND 319/2020 of April 1) [3].

The Commission of Young Allergists and Interns (CAJMIR) of the Spanish Society of Allergy and Clinical Immunology (SEAIC) aimed to assess the impact of the pandemic on the residents' training plan during the first three waves.

A descriptive observational study was conducted using a 14-question survey developed specifically for this purpose with Google forms (see appendix), addressed to Allergy residents of all years. For avoiding more than one answer per person, email address was request.

The survey was distributed through CAJMIR to residents located in different Spanish territories, via email, social networks, and instant messaging platforms. It was completed anonymously and voluntarily. All surveys filled between March 29, 2021 and May 15, 2021 were included.

Descriptive statistics were performed using IBM SPSS v. 20 (IBM corporate, Armonk, New York, USA).

During the pandemic, 204 residents were in Allergy training nationwide. A total of 118 completed surveys were analyzed.

Regular allergy care activity was suspended in $77.1 \%$ of the services to which the respondents belonged. 
Of all participants, $94.9 \%$ performed care activities related to a COVID-19 area; $81.4 \%$ $(\mathrm{n}=96), 72 \%(\mathrm{n}=85)$ and $70.3 \%(\mathrm{n}=83)$ worked in the first, second and third waves of the pandemic, respectively.

A total of $66.9 \%(n=79)$ were on-call in the ER, $26.3 \%(n=31)$ were on ER work shifts, $61 \%(n=72)$ were on-call in the COVID-19 inpatient area and 55.9\% $(n=66)$ were on COVID-19 inpatient work shifts.

The distribution of residents towards COVID-19 areas was not higher in any specific area or community.

Training activities were affected in $82.2 \%$ of cases, $55 \%$ suspended and $27.2 \%$ postponed. Most of the residents $(61.9 \%)$ could not complete their rotations, $86.4 \%$ of them considered that the pandemic resulted in less academic training and in $51.7 \%$, in fewer research opportunities.

The data was broken down by year of residence. Supplementary Table 1.

Of the fourth-year residents, $67.6 \%(n=23)$ missed rotations, $85.2 \%$ of them were unable to make them up. Of these, $11.7 \%(n=4)$ were external rotations, $32 \%(n=11)$ were allergy-specific rotations and $11.7 \% \quad(n=4)$ were complementary allergy training rotations. Residency time was shortened in $32.3 \%(\mathrm{n}=11)$, with loss of 2 months in $17 \%$ $(n=6), 3$ months in $11.7 \%(n=4)$ and 4 months in $2.9 \%(n=1)$. At the end of their training, $94.1 \%(\mathrm{n}=32)$ got jobs, $64.7 \%(\mathrm{n}=22)$ as allergists, $23.5 \%(\mathrm{n}=8)$ with pandemic-specific temporary contracts called "COVID-19 contracts" and 23.5\% $(n=8)$ in the ER, of which $17.6 \%(n=6)$ work simultaneously as allergist and ER physician or in the COVID-19 area. Of the third-year residents, $94 \%(n=31)$ missed rotations, $51.5 \%(n=17)$ related to allergyspecific training, $21.2 \%(n=7)$ to external rotations and $24.2 \%(n=8)$ to complementary allergy training rotations. Only $42 \%(\mathrm{n}=14)$ managed to recover their rotations.

All the second-year residents missed their rotations, of which $11.7 \%(n=2)$ were allergyspecific rotations and $70.5 \%(\mathrm{n}=12)$ were in complementary specialties to their training. About $41 \%$ of them were recovered.

Of the first-year residents, $73.5 \%(n=25)$ missed rotations, $14.7 \%(n=5)$ were from allergy and $70.5 \%(n=24)$ were from other complementary specialties. Of these, $50 \%$ were unable to make up their rotations.

Forty percent of the residents at all levels made proposals to improve the deficits of the training plan and $78 \%$ of them considered that an extension of the residency period would 
be necessary to balance the training lost during the pandemic. On the other hand, 17\% recommended online training courses through scientific societies and 5\% proposed rotations in different hospitals depending on the area of least learning.

The COVID-19 pandemic has had a great impact on the daily tasks of residents and medical staff, even a significant psychological impact [4].

In Spain, allergists and residents have worked in COVID-19 teams in $40.5 \%$ and $92.9 \%$ of cases, respectively [5]. In addition, the use of telemedicine in Allergy Services has been proposed as a useful tool for medical care. [5 y 6].

The training of Allergy residents was affected by the interruption of the training plan in a large proportion of residents, to perform COVID-19-related care activities, especially in emergency and on-call shifts. Most of them consider they have lost training and a lower acquisition of skills related to the specialty, with similar data in surgical and other medical specialties [7-15]. Not all residents were able to make up for lost training. This seems to have affected the last-year residents the most.

A significant proportion of the residents who completed residency training during the pandemic went on to work as specialists, although many of them on COVID-19 or ER contracts, and the long-term duration of these contracts is unknown.

Our survey has several limitations. The questionnaire was anonymous and online, so a non-response bias was inevitable. Some data were missing, since it was designed to be completed quickly. We lacked longitudinal follow-up, so it is unknown how rotations were recovered, if suspended. We recognize the responder's bias and those with strong feelings of being affected by the pandemic might be more prone to respond.

To our knowledge, this study is the first on the impact of the pandemic on resident allergy training. Respondents represented more than 50\% of all residents from diverse geographic regions, so it could be highly representative of this population.

In conclusion, the COVID-19 pandemic had a negative impact on the residency training program of Spanish allergists residents. The future working conditions of young allergists recruited during the pandemic period are unknown. Several proposals were identified, such as expanded residency training, specific rotations or with online learning modalities to facilitate interaction between young allergists and their senior opinion leaders. 


\section{Acknowledgments}

The members of the commission CAJMIR thank the board of directors of Spanish Society of Allergology and Immunology (SEAIC) for their trust in carrying out this study, specially Prof. Ignacio Dávila.

The authors thank all the members of the commission CAJMIR for their effort collecting data.

\section{Fundings}

The authors declare that no funding was received for the present study.

\section{Conflicts of interest}

The authors declare they have no conflicts of interest.

\section{References}

1. Real Decreto 463/2020, de 14 de marzo, por el que se declara el estado de alarma para la gestión de la situación de crisis sanitaria ocasionada por el COVID-19. «BOE» núm. 67, de 14/03/2020. Disponible en: https://www.boe.es/eli/es/rd/2020/03/14/463/con

2. Orden $\mathrm{SND} / 232 / 2020$, de 15 de marzo, por la que se adoptan medidas en materia de recursos humanos y medios para la gestión de la situación de crisis sanitaria ocasionada por el COVID-19. BOE-A-2020-3700. Disponible en: https://www.boe.es/eli/es/o/2020/03/15/snd2328. Ministerio de Sanidad.

3. Orden SND/319/2020, de 1 de abril, por la que se modifica la Orden SND/ 232/2020, de 15 de marzo, por la que se adoptan medidas en materia de recursos humanos y medios para la gestión de la situación de crisis sanitaria ocasionada por el COVID-19. Disponible en: https://www.boe.es/boe/dias/2020/04/03/pdfs/BOE-A-2020-4265.pdf

4. Alsaywid B, Housawi A, Lytras M, Halabi H, Abuzenada M, Sami A, et al. Residents' Training in COVID-19 Pandemic Times: An Integrated Survey of Educational Process, Institutional Support, Anxiety and Depression by the Saudi Commission for Health Specialties (SCFHS). Sustainability. 2020;12:10530. 
5. Fernández-de-Alba I, Brigido C, García-Gutierrez I, Antolín-Amérigo D, Sánchez-García S. COVID-19 and Allergy: Allergists' Workload During the Pandemic. J Investig Allergol Clin Immunol. 2021;31(2):187-90.

6. González-Pérez R, Sánchez-Machín I, Poza-Guedes P, Matheu V, Álava-Cruz C, Mederos LE, et al Pertinence of Telehealth in a Rush Conversion to Virtual Allergy Practice During the COVID-19 Outbreak. Allergy Department, Hospital Universitario de Canarias, Tenerife, Spain. J Investig Allergol Clin Immunol. 2021;31(1):78-80.

7. Lo HY, Lin SC, Chaou CH, Chang YC, Ng CJ, Chen SY. What is the impact of the COVID-19 pandemic on emergency medicine residency training: an observational study. BMC Med Educ. 2020;20(1):348.

8. Richards M, DeBonis K. Psychiatric Training During a Global Pandemic: How COVID-19 Has Affected Clinical Care, Teaching, and Trainee Well-Being. Psychiatr Serv. 2020;71(12):1300-2.

9. Hilmi M, Boilève A, Ducousso A, Michalet M, Turpin A, Neuzillet C, et al. Professional and Psychological Impacts of the COVID-19 Pandemic on Oncology Residents: A National Survey. JCO Glob Oncol. 2020;6:1674-83.

10. Cuffaro L, Carvalho V, Di Liberto G, Klinglehoefer L, Sauerbier A, GarciaAzorin D, et al. Neurology training and research in the COVID-19 pandemic: a survey of the Resident and Research Fellow Section of the European Academy of Neurology. Eur J Neurol. 2021;28(10):3437-42.

11. Samimi S, Choi J, Rosman IS, Rosenbach M. Impact of COVID-19 on Dermatology Residency. Dermatol Clin. 2021;39(4):609-18.

12. Awadallah NS, Czaja AS, Fainstad T, McNulty MC, Jaiswal KR, Jones TS, et al. The impact of the COVID-19 pandemic on family medicine residency training. Fam Pract. 2021;38(Suppl 1):i9-i15

13. Votto M, De Filippo M. On behalf of the Pediatric Residents of the University of Pavia, Italy. How pediatric resident's life has changed during the COVID-19 pandemic. Ital J Pediatr. 2020;46:156.

14. Yadav A. Cardiology training in times of COVID-19: Beyond the present. Indian Heart J. 2020;72(4):321-4. 
15. Seidel B, Trovato E, Elashvili M, Bartels M, Oh-Park M, Thomas M, et al. Impact of the COVID-19 Pandemic on Physical Medicine and Rehabilitation Residency in the Epicenter of the Outbreak. Am J Phys Med Rehabil. 2020;99(9):784-6. 